\title{
MANAGEMENT OF PATIENTS WITH FIBROMYALGIA USING BIOFEEDBACK: A RANDOMIZED CONTROL TRIAL
}

\section{ABRAHAM S. BABU, ELSA MATHEW, DEBASHISH DANDA*, HENRY PRAKASH ${ }^{\star \star}$}

\section{ABSTRACT}

OBJ ECTIVE: Fibromyalgia syndrome (FMS) is a chronic rheumatological condition which could be characterized by generalized pain and fatigue. Cognitive and behavioral therapy has been found to be a suitable technique in the management of FMS. This study intends to evaluate the efficacy of electromyography (EMG) biofeedback to reduce pain in patients with FMS. MATERIALS AND METHODS: A randomized controlled trial involving two groups of FMS patients, one receiving EMG biofeedback and the other a sham biofeedback, was carried out. The assessment tools included in the study were fibromyalgia impact questionnaire (FIQ), visual analogue scale (VAS), six-minute walk test (SMWT) and number of tender points; and tenderness of each tender point was done for both the groups. STATISTICS: A Student's ' $t$ ' test was used to study the test for significance. RESULTS: After using biofeedback, the mean VAS scores and the mean number of tender points were found to be 3 out of 10 and 6 out of 18 respectively. Subjective analysis from both groups showed improvement in physical and psychological realms. Statistical significance $(P<0.001)$ was observed for decrease in pain and number of tender points. ANOVA analysis revealed a significant decrease in VAS, FIQ and tender points within the groups. CONCLUSION: Biofeedback as a treatment modality reduces pain in patients with FMS, along with improvements in FIQ, SMWT and the number of tender points.

Key words: Biofeedback, fibromyalgia, fibromyalgia syndrome, physical therapy, physiotherapy, rehabilitation

Fibromyalgia syndrome (FMS) is a chronic rheumatological condition characterized by musculoskeletal pain, stiffness, paresthesia, disturbed sleep, easy fatigability, along with multiple painful tender points that are widely and symmetrically distributed in the human

Departments of Physiotherapy, *Clinical Immunology and Rheumatology, ${ }^{* *}$ Physical Medicine and

Rehabilitation, Christian Medical College, Vellore, India

Correspondence:

Dr. Abraham Samuel Babu, Department of Rehabilitation, E-mail: abrahambabu@gmail.com body. ${ }^{[1,2]}$ The diagnosis of FMS is made by clinical examination and using the American College of Rheumatology (ACR) criteria $1990 .{ }^{[2]}$

Therapies available for FMS include pharmacological interventions with selective serotonin reuptake inhibitors (SSRIs), tricyclic antidepressants, opioids, muscle relaxants and others. ${ }^{[3]}$ Nonpharmacological interventions include physical therapy, massage, cognitive behavior therapy and alternate therapies. ${ }^{[4]}$
Studies reveal that physical therapy involving exercises provides better results compared to electrotherapy modalities. ${ }^{[5]}$ It is observed that the best mode of treatment of FMS is a multimodal combination of physical, cognitive and pharmacological interventions. ${ }^{[6]}$

Biofeedback is a new mode of treatmen for the management of FMS. ${ }^{[7-9]}$ This mode of treatment uses computers and surface electrodes that are placed on the skin of the person to reveal their internal physiological events, in the form of visual and auditory signals. This is one of the electrotherapeutic modalities in physical therapy, by which a person learns to control physiological processes that are usually involuntary, through auditory and visual stimuli. This modality has been used in the management of temporomandibular joint dysfunctions, patellofemoral pain, hypertension, spasticity and cerebrovascular accidents. Relaxation and facilitation of muscles are some of the main areas of treatment using biofeedback in physical therapy. ${ }^{[7,10,11]} \mathrm{A}$ few studies have reported, without strict methodological rigor, on biofeedback being used to facilitate and train relaxation in chronic pain. ${ }^{[12-14]}$ In order to achieve this, biofeedback is targeted to the muscle groups of the forearm extensors, trapezius and frontalis. Biofeedback utilizes the principle of hypostimulation (relaxation) of the central nervous system, which increases the endorphins and forms the neuroendocrine basis of biofeedback for control of chronic pain. ${ }^{[15]}$

This study intends to demonstrate the effect of biofeedback on pain management of patients with FMS. Additional factors such as aerobic endurance, number of tender points and function are included in the study to determine the effects of biofeedback.

\section{MATERIALS AND METHODS}

A double-blinded randomized control trial was carried out on 30 patients attending the outpatient department who fulfilled the ACR criteria. ${ }^{[16]}$ Patients excluded were those with majo psychiatric disorders, malignancies, osteomalacia New York Heart Association (NYHA) class 3 and 4 , recent stroke or myocardial infarction, rena failure and neuropathic pain. The study was cleared by the local ethical committee of the institution, and informed consent was obtained prior to the treatment.

The assessment tools included in the study were as follows:

- Visual analogue scale (VAS) to measure pain

- Fibromyalgia impact questionnaire (FIQ) to assess the function

- Six-minute walk test (SMWT) to assess aerobic fitness

- Number of tender points

These were assessed prior to the start of treatment and also after the 6-day treatment sessions. The FIQ included questions to assess physical, psychological and functional realms, and the number of tender points were assessed using the ACR criteria.

Patients were randomly categorized into two groups as given below:

Group 1: Experimental (patients who received true biofeedback)

Group 2: Control (patients who received sham biofeedback) 
The biofeedback equipment (silver electrodes $4 \mathrm{~mm}$ in diameter connected to the computer through an amplifier) and software were designed in the institution by the Department of Bioengineering. A continuous 6-day treatment schedule of EMG biofeedback was given to both the groups, with each session lasting 45 min. The sham biofeedback was administered through modification of the software, which was done by the designer. This provided a constant visual feedback to the patient, irrespective of the muscle activity.

Treatment was given to the forearm extensors, upper trapezius and frontalis as recommended by Basmajian et al. ${ }^{[15]}$ Patients were taught to relax through techniques like positioning, breathing and hold-relax with the help of visual and auditory feedback. Patients were gradually taught how to include relaxation into their activities of daily life. At the end of 6 days, both groups received a home program consisting of gentle stretching and aerobic training. ${ }^{[17]}$ They were also taught coping and pacing strategies.

\section{Statistical analysis}

Descriptive statistics used to compare the two trial groups with respect to baseline values included mean and standard deviations for quantitative variables and proportions and percentages for categorical variables. The primary outcome measure was the mean difference between the two groups in change of the VAS pain score. Also change in FIQ, mean scores from six-minute walk test and tender points were analyzed. The change in scores was treated as continuous normally distributed data.

Analysis of outcome measure was done in two stages. The first stage determined whether there was a significant change in outcome from the baseline for the two groups and was assessed using paired ' $t$ ' test. The mean difference of scores between two groups was assessed using independent ' $\mathrm{t}$ ' test. The second stage involved repeated measures using ANOVA for the hypothesis that pain scores will decrease in both groups.

\section{Sample size}

A sample size of 15 patients per group was calculated to detect a difference of $5 \mathrm{~cm}$ between group 1 and group 2 on the VAS. An alpha error threshold of 0.05 for statistical significance was set.

\section{RESULTS}

The average age of the patients was 39 years, which included 21 females and 9 males. Table 1 shows the two trial groups were similar on most baseline characteristics, except that the mean age was higher in the treatment group. Figure 1 summarizes the flow and retention of participants. Thirty met the study criteria and were randomized: 15 to biofeedback and 15 to sham.

The statistical analysis using Student 't' test revealed that there was a significant decrease in pain and the number of tender points on

\begin{tabular}{lcc}
\multicolumn{4}{c}{ Table 1: Comparison of baseline characteristics } \\
\hline Characteristic & $\begin{array}{c}E M G \text { group } \\
(n=15)\end{array}$ & $\begin{array}{c}\text { Sham group } \\
(n=15)\end{array}$ \\
\hline Mean Age (SD) & $43.2(10.5)$ & $35.3(9.7)$ \\
Sex & $3(20)$ & $5(33)$ \\
Male $n(\%)$ & $12(80)$ & $10(67)$ \\
Female $n(\%)$ & $7.1(1.8)$ & $8.1(1.8)$ \\
Mean VAS (SD) & $61(13.3)$ & $65(15.6)$ \\
Mean FIQ (SD) & $314.5(63.4)$ & 309.1 (81.3) \\
Mean MWT (SD) & $15.2(2.5)$ & $13.9(2.6)$ \\
Mean TP (SD) & & \\
\hline
\end{tabular}

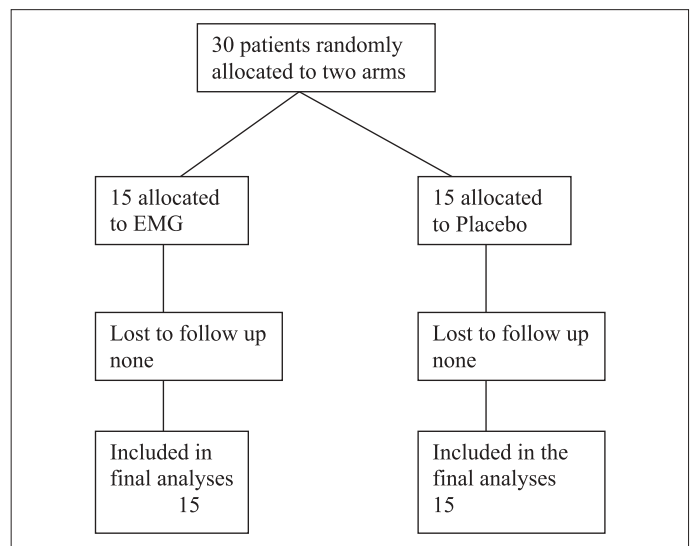

Figure 1: Description of the flow and retention of participants in the study

comparison between the groups $(P<0.01)$. However, changes in the FIQ scores and SMWT were not statistically significant $(P>$ 0.01 ). Mean VAS scores prior to treatment in group 1 and group 2 were 7.5 and 8.13 respectively. Following treatment, the mean scores decreased to 3 in group 1 and 5 in group 2. Repeated-measures ANOVA for VAS pain scores showed a significant within-subject effect of time and between-subject effect $(F=$ 12.23, $P=0.002$; and $\mathrm{F}=57.98, P=0.000$ ), but the interaction between time and treatment was not significant $(F=3.08, P=0.09)$. Figure 2 shows mean VAS scores before and after treatment in both the groups.

$$
<\text { or }
$$

For the tender points, there was larger decrease in tender points between the two groups $(P=$ 0.002). Patients in group 1 showed a greater decrease in tender points than those in group 2. In group 1, the mean number of tender points after treatment was 6 , while in group 2 it was 10. This change was statistically significant $(P$ $<0.01$ ). Figure 3 shows the mean number of tender points in both the groups before and after treatment. Repeated-measures ANOVA

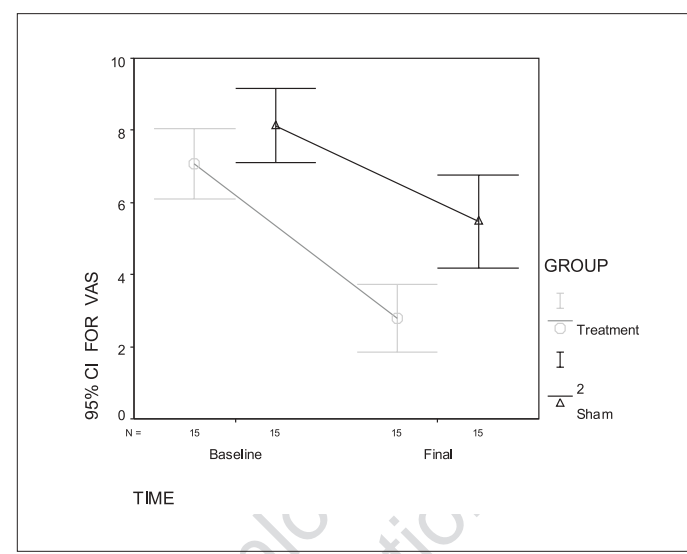

Figure 2: Comparison of VAS scores for pain between the two groups

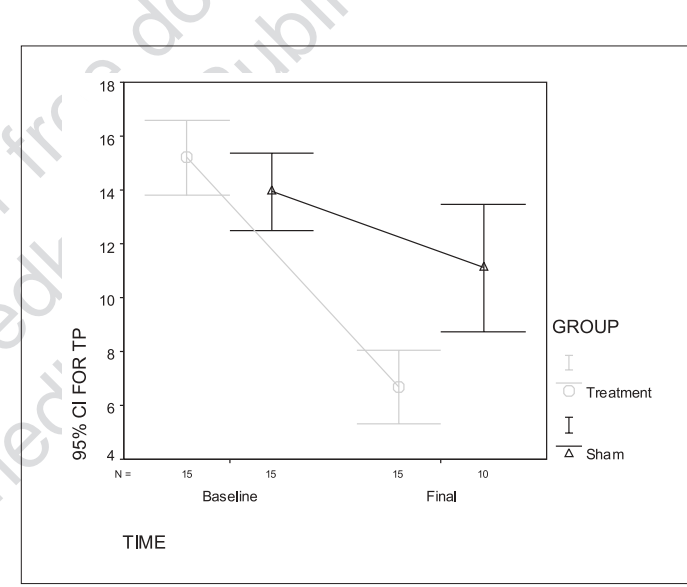

Figure 3: Comparison of the number of tender points between the two groups

for tender points showed a significant within subject effect of time and interaction between time and treatment $(F=104.63, P=0.000$ and $F=66.15, P=0.003)$, but the betweensubject effect was not significant $(F=0.67, P$ $=0.421$ ).

For each outcome, Table 2 compares the mean change between baseline and fina assessment for the two trial groups. Fo the $F I Q$, there is a statistically significan decrease in both the groups, but the decrease 
Table 2: Mean changes from baseline in outcome measures

\begin{tabular}{|c|c|c|c|}
\hline Outcome & $E M G(n=15)$ & Sham $(n=15)$ & $P$ valu \\
\hline $\begin{array}{l}\text { FIQ } \\
\text { VAS }\end{array}$ & $\begin{array}{l}-21.9(-28,-15) \\
-4.3(-5.3,-3.3)\end{array}$ & $\begin{array}{r}-12.3(-20.8,-4.2) \\
-2.6(-4.4-1)\end{array}$ & \\
\hline & $-8.6(-10.9,-6.3)$ & $-4.4(-5.9,-2.9)$ & 0.06 \\
\hline SMWT & & 16 & 0.0 \\
\hline
\end{tabular}

Change scores from baseline: mean (95\% confidence interval). FIQ, fibromyalgia impact scale; VAS, visual analogue scale; TP, tender points; SMWT, six-minute walk test distance in meters

is larger in the treatment group than the control group $(0.05<P<0.10$ for the two tailed test). A statistically significant decrease in both the groups for VAS pain scores was seen, but the decrease was marginally larger in the treatment group $(0.05<P<0.10)$ for the two tailed test. For the tender points, there was larger decrease in tender points between the two groups ( $P=$ 0.002).

The results of repeated-measures ANOVA for FIQ showed a significant within-subject time effect ( $F=48.32, P=0.000)$, but the betweensubject group effect and interaction between time and group were not significant $(F=2.786$, $P=0.106$; and $\mathrm{F}=3.594, P=0.698$ ). Repeatedmeasures ANOVA for mean six-minute walk test distance showed a significant within-subject effect of time $(F=8.325, P=0.007)$, but the between-subject effect and interaction between time and treatment were not significant $(\mathrm{F}=$ $0.540, P=0.469$; and $F=1.146, P=0.293$ ). Repeated-measures ANOVA for tender points showed a significant within-subject effect of time and interaction between time and treatment $(\mathrm{F}$ = 104.63, $P=0.000$; and $\mathrm{F}=66.15, P=0.003$ ), but the between-subject effect was not significant $(\mathrm{F}=0.67, P=0.421)$.

Patients in group 1 showed a greater decrease in tender points than those in group 2. In group 1 , the mean number of tender points after treatment was 6 , while in group 2 it was 10 . This change was statistically significant $(P<$ 0.01 ). Figure 2 shows the mean number of tender points in both the groups before and after treatment. Repeated-measures ANOVA for tender points showed a significant withinsubject effect of time and interaction between time and treatment $(F=104.63, P=0.000$; and $\mathrm{F}=66.15, P=0.003$ ), but the betweensubject effect was not significant $(F=0.67, P$ $=0.421$ ).

The SMWT after treatment showed an increase in distance of $65.8 \mathrm{~m}$ in group 1 and $7.86 \mathrm{~m}$ in group 2.

\section{DISCUSSION}

Lack of epidemiological data in India makes it difficult to judge the incidence of FMS. The FMS is more commonly seen in women in the age group of 30-50 years than in men, and the ratio is of the order of 9:1. ${ }^{[2]} \mathrm{A}$ similar incidence was also observed here and is shown in Table 3.

The current study was a double-blinded placebo controlled trial which was done using biofeedback as the treatment modality. The initial and final scores of pain were assessed using the VAS and the aerobic endurance with the SMWT. The number of tender points according to the ACR criteria and the FIQ scores were the validated tools to assess patients with FMS. ${ }^{[16,18]}$

As reported by Pankoff et al., the SMWT

\section{Table 3: Demographic table}

\begin{tabular}{lcc}
\hline Group & Age (Yrs) & Sex (M:F) \\
\hline Biofeedback (BF) & $43 \pm 10$ & $4: 11$ \\
Placebo & $35 \pm 9$ & $5: 10$ \\
\hline
\end{tabular}

distance has been shown to be less in patients with FMS. ${ }^{[19]}$ A change in mean distance between the groups was however not demonstrated in this study, though there was a much higher change in mean distance between the initial and final distances within the group. In group 1, one patient was unable to complete the SMWT because of giddiness, palpitations and dyspnea. This, along with the small sample size of the study, could have been a factor leading to statistical insignificance for the SMWT.

There was a statistically significant decrease in the VAS scores for pain within the group as well as between the groups. This decrease observed after treatment is in support of the analgesic effects of biofeedback as reported by Ferrocoli et al. ${ }^{[12]}$

One patient in group 1 reported no improvement after treatment. This was the result of severe psychosomatization, which was diagnosed and treated later.

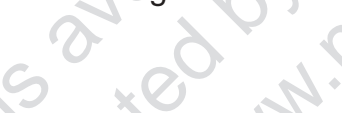

Patients in group 1 had a decrease in FIQ scores from 65.2 to 38.67 (22\%), while those in group 2 had a decrease from 61 to 50.6 (12.6\%) only. A significant change was seen in each group $(P=0.05)$. Though no statistical difference was seen between the groups, a subjective improvement was observed.

From the current study, it is revealed that the use of VAS, FIQ, number of tender points and SMWT as biofeedback tools has influenced significantly the management of patients with FMS. Hence it is suggestive of adopting this technique for FMS patients parallel to medical management. A home program of relaxation and coping and pacing strategies involves the patients in the management of their symptoms The ability of patients to perform relaxatio once it has been learned through biofeedback makes it easy and safe for long-term use. However, long-term follow-up will be required to determine the benefits of this treatmen modality and patient compliance to the home program. A comparison of biofeedback with other electrotherapeutic modalities will also help physiotherapists in the management of FMS.

\section{CONCLUSION}

mong the vast treatment options of exercises and various alternative therapies, biofeedback is a new modality, which has been investigated in this study. However, this vital technique used in the management of FMS has to be widely used in the clinical scenario to get a healthy outcome. From the results of this study, it is clear that biofeedback is an effective mode of treatment in the management of FMS especially in decreasing the pain and number of tender points.

\section{ACKNOWLEDGMENT}

The authors thank the Ethical Committee of the Christian Medical College and Hospital, Vellore, and the Fluid Research Grant for granting permission and providing the funding for the study respectively. The authors would like to gratefully acknowledge the help extended by Dr. Suresh Devasahayam, Mr. Lenny Vasanthan T., Mr. David V. Samuel, Ms. Priyanka Goyal and Ms. Ruplekha Kumbhakar for this study. The authors specially mention the names of Dr. Sunderlal Babu and Dr. Pradeep John Promod for their guidance. 


\section{REFERENCES}

1. Scudds RA, Charron J, Santilli D, Li CW, Scudds RJ. A survey of people with fibromyalgia on the perceived usefulness of physical therapy. Abstracts of the Canadian Physiotherapy Association of National Congress: Victoria, British Columbia; 1996. p. 7.

2. Harrison's Principles of Internal Medicine. In: Kasper DL, Fauci AS, Lango DL, Braunwald E, Hauser SL, Jamison JL, editors. $16^{\text {th }}$ ed. McGraw Hill Publications: 2004. p. 2055-7.

3. Mease P. Fibromyalgia syndrome: Review of clinical presentation, pathogenesis, outcome measures and treatment. J Rheumatol Suppl 2005;75:6-21.

4. Frontera WR, Silver JK. Essentials of Physical Medicine and Rehabilitation Haley and Bulfus Inc. FIBROMYALGIA: Joanne Borg Stein. p. 559-62.

5. Sim J, Adams N. Physical and other nonpharmacological interventions for fibromyalgia. Baillieres Best Pract Res Clin Rheumatol 1999;13:507-23.

6. Adams N, Sim J. Rehabilitation approaches in fibromyalgia. Disabil Rehabil 2005;27:711-23.

7. O'Sullivan SB, Schmitz TJ. Physical rehabilitation assessment and treatment. $4^{\text {th }}$ ed. Jaypee Brothers: p. 1093-115.

8. Mur E, Drexler A, Gruber J, Hartig F, Gunther V. Electromyography biofeedback therapy in fibromyalgia. Wien Med Wochenschr 1999;149:561-3.

9. Mannerkorpi K, Svantesson U, Broberg C. Relationships between performance-based tests and patients' ratings of activity limitations, selfefficacy and pain in fibromyalgia. Arch Phys Med Rehabil 2006;87:259-64.

10. Yip SL, Ng GY. Biofeedback supplementation to physiotherapy exercise programme for rehabilitation of patellofemoral pain syndrome: $A$ randomized controlled pilot study. Clin Rehabilit
2006;20:1050-7.

11. Medlicott MS, Harris SR. A systematic review of the effectiveness of exercise, manual therapy, electrotherapy, relaxation training, and biofeedback in the management of temporomandibular disorder. Phys Ther 2006;86:955-73.

12. Ferraccioli G, Ghirelli L, Scita F, Nolli M, Mozzani M, Fontana S, et al. EMG-biofeedback training in fibromyalgia syndrome. J Rheumatol 1987;14:820-5.

13. Sarnoch H, Adler F, Scholz OB. Relevance of muscular sensitivity, muscular activity and cognitive variables for pain reduction associated with EMG biofeedback in fibromyalgia. Percept Mot Skills 1997;84:1043-50.

14. Mur E, Drexler A, Gruber J, Hartig F, Gunther V. Electromyography biofeedback therapy in fibromyalgia. Wien Med Wochenschr 1999;149:561-3.

15. Basmajian V. Part I - Introduction neuroscience Biofeedback: Principles and practice for clinicians. $3^{\text {rd }}$ ed. John, Williams and Wilkins: p. 1-4.

16. Wolfe F, Smythe HA, Yunus MB, Bennett RM, Bombardier C, Goldenberg DL, et al. The American College of Rheumatology 1990 criteria for the classification of fibromyalgia: Report of the multicenter criteria committee. Arthritis Rheum 1990;33:160-72.

17. Offenbächer M, Stucki G. Physical therapy in the treatment of fibromyalgia. Scand J Rheumatol Suppl 2000;113:78-85.

18. Burckhardt CS, Clark SR, Bennett RM. The fibromyalgia impact questionnaire: Development and validation. J Rheumatol 1991;18:728-33.

19. Pankoff B, Overend T, Lucy D, White K. Validity and responsiveness of the 6 minute walk test for people with fibromyalgia. J Rheumatol 2000;27:2666-70.

Source of Support: Nil, Conflict of Interest: None declared. 